\title{
Assessment of hazardous material risks for rail yard safety
}

\author{
Theodore S. Glickman ${ }^{\mathrm{a}, *}$, Erhan Erkut ${ }^{\mathrm{b}}$ \\ ${ }^{a}$ School of Business, George Washington University, Washington, DC 20052, USA \\ ${ }^{\mathrm{b}}$ Bilkent University, Faculty of Business Administration, Bilkent, Ankara, Turkey
}

Received 20 October 2005; received in revised form 23 September 2006; accepted 26 September 2006

\begin{abstract}
This paper illustrates the application of quantitative risk assessment in a rail yard where tank cars of hazardous materials are received and stored. The assessment was conducted in response to community concerns about the safety of a proposed yard expansion. Six different chemicals are involved. For each one, the average monthly volume and the hazard of most concern are specified. We use an event tree populated with empirical data to compute the probability of a major spill in each case and we estimate the corresponding critical impact distances using available modeling tools. We find that for some of the chemicals, the relative increases in risk are appreciable, but that in all cases, the absolute levels of risk remain low. Then we identify some ways in which such an analysis can be extended and discuss the potential difficulties associated with these extensions.
\end{abstract}

(C) 2006 Elsevier Ltd. All rights reserved.

Keywords: Risk assessment; Hazardous materials; Transportation; Rail road; Rail yard; Safety

\section{Introduction}

This paper describes an analysis of an actual situation in which a manufacturer, in order to increase its production volume, needed to expand the rail yard in which it receives and stores the hazardous materials it uses as process inputs. The adjacent community expressed concern about the safety implications of this decision and in response the

\footnotetext{
* Corresponding author. Tel.: +1 202994 4791; fax: +1 2029942736.

E-mail addresses: glickman@gwu.edu (T.S. Glickman), erkut@bilkent.edu.tr (E. Erkut).
} 
manufacturer offered to conduct a risk assessment study. Six different chemicals were addressed, all of which are shipped in tank cars which are stored in the yard while the contents are consumed. The objective of the analysis was to use railroad industry data to accurately estimate the frequencies of the events leading up to major spills in similar situations involving similar tank cars, and then to use standard methods to estimate the impact areas of such spills. For frequency estimation purposes, we used a combination of public data maintained by the Federal Railroad Administration of the US Department of Transportation, and proprietary data maintained by the Association of American Railroads. For impact estimation purposes, we used the models and procedures made available by the US Environmental Protection Agency (USEPA) for compliance with the consequence reporting requirements of its Risk Management Program.

In general, the transportation and storage of hazardous materials offers challenges to all stakeholders involved (shippers, carriers, car owners, receivers, workers, local residents, emergency responders, and other public officials) due to the possibility of release incidents and the risks associated with them. The low probability-high consequence nature of major hazardous material spills attracts considerable public attention. An incident resulting in a large spill will often have serious environmental and health consequences, not to mention considerable financial liability. Because a catastrophic incident can have a significant economic impact on the responsible party or parties and on the other stakeholders, everyone involved has an interest in assessing and reducing the risks. While transport risks along the routes are very important, risks associated with the use of rail yards for car classification en route and tank car movement and storage in yards and along sidings at the destinations cannot be ignored. The fact that yard risks have received so little attention in the research literature heretofore is probably due to a combination of two factors: (1) the perception that these risks are less important than mainline risks, and (2) the relative scarcity of yard-related exposure and accident data.

\section{Literature}

Given the significance of hazardous material release incidents for the businesses, employees, and public parties involved, researchers have paid considerable attention to and produced abundant literature on the assessment of hazardous material risks in every mode of transportation. Purdy (1993) offers a tutorial on hazardous material transport risk assessment, as well as a case study that compares the road and rail risks for the transport of chlorine in England. It finds that rail transport risks are considerably higher than road transport risks in those circumstances, primarily because railroads tend to go through cities while the highway system is designed to go around cities. Cassidy (1993) summarizes a major hazardous material transport risk study conducted in England that assesses the risks associated with hazardous materials in rail transport as well as fixed facilities, and develops the concept of risk tolerability in this context.

While a considerable portion of the hazardous material road transport literature deals with route selection, this is not as relevant an issue for hazardous material rail transport since the rail network in most countries is considerably sparser than the road network and the number of practical alternative routes between most origin-destination pairs is small, particularly over short distances. Hence, much of the rail hazardous material safety literature has focused on assessing the risks on routes. For example, Alp et al. (1993) assess hazardous material transport risks imposed by rail shipments through Toronto and 
Olekszyk (1993) considers the routing of spent nuclear fuel waste to the Yucca Mountain repository site in Nevada and provides a summary of the attributes of selected routes. Glickman and Erkut (1996) examine the tradeoffs between economic and safety factors for a representative set of railroad routes.

While a number of studies assess rail transport risks, only a few studies report on risks at rail yards. CCPS (1995) suggests that rail yards tend to be forgotten when risk assessment activities are prioritized. Other authors have recognized that the risks associated with the endpoints of the routes need to be addressed. For example, Kirchner and Rhyne (1993) focus on risks due to loading and unloading at industrial facilities. Comparing facility risks with transport risks, they conclude that handling risks can be higher than transport risks in certain cases. ACDS (1991) and CCPS (1995) include case studies that take into account rail yard risks in chlorine transport. Both studies find that, while the risks associated with yards are lower than those associated with transport, they are not negligible.

The risk assessment at a rail yard has features in common with the risk assessment for transport routes and fixed facilities. Erkut and Verter (1998) provide a tutorial on the modeling of en-route hazardous material transport risk and offer an empirical comparison of different approaches to the modeling of risk. Other sources containing extensive bibliographies, particular with regard to European research in transport risk assessment, include Nicolet-Monnier and Gheorghe (1996) and Vogel and Vondra (2001). More recently, Barkan et al. (2003) argue that rail risks need to be analyzed from the perspective of cause identification and reduction.

\section{Methodology}

In quantitative risk assessment, risk is defined as the product of the probability of an undesirable event and its consequence. The probability can be estimated directly based on historical data or computed in stages using event tree analysis. For the case study considered here the methodology used is as follows:

- Identify the various hazardous materials shipped to the rail yard, along with the tank car type and size used for each one.

- For each such hazardous material, perform the following steps:

1. Determine the hazard of concern as well as its critical level.

2. Establish the average monthly volume of transport.

3. Compute the probability of a major spill.

4. Estimate the worst-case impact radius.

Due to data limitations, executing Step 3 requires decomposing the probability sought into a sequence of probabilities that can be estimated from the available data. This is a technique that was developed by Glickman and Rosenfield (1984). The execution of Step 4 relies on the use of a release consequence model for Gaussian plume dispersion in the case of gases and for fire and explosion impacts in the case of the other hazardous materials of concern. Instead of endeavoring to capture a lot of extraneous detail involving high levels of uncertainty by factoring in wind and temperature variations, time of day variations, and alternative puncture and leak scenarios, which would have been beyond the necessary scope of the analysis, we opted to rely on EPA software that calculates the worst-case circular impact radius for each chemical involved. 
Understanding the process used to estimate major spill probabilities is simplified by envisioning an event tree with three levels. At the first level the initiating event occurs either when the tank car is moving or not moving, at the second level a release either happens or does not, and at the third level, the release size is either large or not large. This event tree, which applies to every hazardous material tank car that is handled in the rail yard, takes into account all possible causes of release. We use the term "accidents" to refer to initiating events that occur when cars are moving (e.g., a collision and derailment) and "non-accidents" to refer to initiating events that happen when they are stationary (e.g., failure of a tank car fitting or unintentional disconnection of a hose).

To reduce the burden of data collection and reporting, the available industry data is confined to "large releases", i.e., those releases in which at least $80 \%$ of the tank car contents are lost. Hence this risk assessment is also limited to releases of this magnitude, which is consistent with the focus on major spills. The final outcomes in the event tree relate to whether or not the release is a large one. Each path through the tree represents a scenario, each of which has a probability equal to the product of the probabilities for the three sequential events. The two scenarios of interest are:

(a) A large release accident:

- A tank car visiting a yard is involved in an accident (while moving or stationary).

- The accident causes the tank car to start releasing its contents.

- The total amount released turns out to be at least $80 \%$ of the contents.

(b) A large release non-accident:

- A tank car (moving or stationary) is not involved in a yard accident.

- The tank car starts to release its contents for non-accident reasons.

- The total amount released turns out to be at least $80 \%$ of the contents.

If we define the following notation: $A=$ tank car accident involvement, $N=$ no tank car accident involvement, $R=$ release occurrence, and $L=$ large release size, then the probability calculations corresponding to the sequence of events in (a) and (b) are, respectively,

$$
\begin{aligned}
& P(A R L)=P(A) P(R \mid A) P(L \mid R, A), \\
& P(N R L)=P(N) P(R \mid N) P(L \mid N, A),
\end{aligned}
$$

where $P(N)=1-P(A)$. Clearly, the probability of a large release is then $P(R L)=$ $P(A R L)+P(N R L)$. Historical industry data can be used to estimate the probabilities in each model, taking into account the chemical's properties and the type of tank car used.

The risk of a large release is then

$$
\mathscr{R}=P(R L) \times r^{*},
$$

where $r^{*}$ is the radius of the "critical impact area", defined as the area in which the impact of the hazard of concern is considered to be at a critical level, assuming that the impact area is circular. There are various possible impacts of concern (fire, explosion, toxic vapor, etc.) and various ways to measure criticality (e.g., immediate danger to life or health (IDLH) and concentration fatal to $50 \%$ of the exposed population $\left(\mathrm{LC}_{50}\right)$ ). These depend on the particular hazardous material involved and the nature of the situation. These concepts are explained in more detail in the consequence analysis report published by USEPA (1999). 


\section{Application}

The railroad yard being considered for expansion is adjacent to a manufacturer of plastic resins and petrochemicals in a heavily industrialized area. The manufacturer receives six different chemicals by train on a regular basis. These chemicals, all of which are classified as hazardous materials, are shipped in tank cars. The manufacturer stores the loaded tank cars on nine of the 11 tracks in the yard in order to have the chemicals available for its production processes. The other two tracks are used for inbound and outbound trains. After each tank car is emptied at the plant it is returned to the yard for pick-up. Hence, the yard serves primarily as a raw materials warehouse for the plant. In anticipation of an increase in production volume, the manufacturer wants to expand the yard to accommodate higher volumes of the six required chemicals. The plan is to add ten additional tracks, of which eight will be used for storage. The goal of the quantitative risk assessment study is to compute and compare the pre-expansion and post-expansion risks.

The yard is operated in accordance with the following rules: speed is limited to $15 \mathrm{mph}$; transport to and from the plant to the yard is restricted to daylight hours; the railroad drops off full tank cars after midnight; and the railroad picks up empty cars after 6 pm. The six chemicals are listed in Table 1 along with the tank car type and the average monthly volume before and after the expansion. With the yard expansion, the volumes of vinyl chloride, sodium hydroxide, and propylene will increase by approximately $20 \%$. The most significant increase in volume $(74 \%)$ occurs for monoethylene glycol. The volumes of hexane and hexane in the rail yard will not change.

The critical radius $r^{*}$ referred to in Eq. (2) is based on a $100 \%$ release, whereas the a large release probability $P(R L)$ is based on a release of $80 \%$ or more. To be exact, we would have had to integrate the product of the probability and the critical radius over release probabilities ranging from $80 \%$ to $100 \%$ to compute the total risk of releases of at least $80 \%$. Instead, we compute an estimate of that risk which is conservatively high, given that we use only the $r^{*}$ value for a $100 \%$ release instead over the range from $80 \%$ to $100 \%$.

Table 2 shows the assumed magnitude of a 100\% release of each chemical, based on the capacity of the specific tank car model used. The critical levels depend on whether the selected hazard is an explosion, direct contact, or a pool fire.

Table 1

Chemical names, related tank car types, and shipment volumes

\begin{tabular}{llcc}
\hline Chemical & Tank car type & Carload volume (cars/month) \\
\cline { 3 - 4 } & & Before & After \\
\hline Vinyl chloride & Pressurized & 8.9 & 10.5 \\
Sodium hydroxide & Non-pressurized & 12.7 & 15.7 \\
Monoethylene glycol & Non-pressurized & 11.0 & 19.1 \\
Propylene & Pressurized & 4.7 & 5.7 \\
Hexene & Pressurized & 0.1 & 0.1 \\
Hexane & Pressurized & 0.1 & 0.1 \\
\hline
\end{tabular}

a $50 \%$ solution. 
Table 2

Release amounts, selected hazards, and critical hazard levels

\begin{tabular}{llll}
\hline Chemical & $100 \%$ Release amount (gallons) & Selected hazard & Critical hazard level \\
\hline Vinyl chloride & 29200 & Explosion & Overpressure $=1 \mathrm{psi}$ \\
Sodium hydroxide & 16700 & Direct contact & Pool depth $=1 \mathrm{~cm}$ \\
Monoethylene glycol & 24600 & Pool fire & Radiation level $=5 \mathrm{~kW} / \mathrm{m}^{2}$ \\
Propylene & 33900 & Explosion & Overpressure $=1 \mathrm{psi}$ \\
Hexene & 33900 & Pool fire & Radiation level $=5 \mathrm{~kW} / \mathrm{m}^{2}$ \\
Hexane & 33900 & Pool fire & Radiation level $=5 \mathrm{~kW} / \mathrm{m}^{2}$ \\
\hline
\end{tabular}

a Assuming release amount equals tank car capacity.

Table 3

Probabilities used for risk calculations (by tank car type)

\begin{tabular}{lll}
\hline Probability $^{\text {a }}$ & Pressurized & Non-pressurized \\
\hline$P(A)$ & 0.000025 & 0.000025 \\
$P(R \mid A)$ & 0.0284 & 0.1469 \\
$P(L \mid R, A)$ & 0.37 & 0.51 \\
$P(N)$ & 0.999975 & 0.999975 \\
$P(R \mid N)$ & 0.0004 & 0.0011 \\
$P(L \mid N, R)$ & 0.0000 & 0.0009 \\
\hline
\end{tabular}

a Based on Association of American Railroads data.

\subsection{Probabilities}

In this section we describe how we used the methodology introduced in Section 3 to estimate the large release probability $P(L R)$ (i.e., the frequency of large releases per tank car) before and after the proposed yard expansion. The values used for the calculations in Eqs. (1a) and (1b), based on historical industry data, are summarized in Table 3.

The accident probability $P(A)$ is equal to one in 40000 . This is the accident rate per tank car that enters the rail yard, and it is the same for both pressurized and non-pressurized tank cars. In other words, only one in every 40000 tank cars entering the yard is involved in an accident. Considering the total volume of 51.2 cars per month after the expansion, or 614.4 cars per year, the mean time between such accidents would be about 65 years.

The conditional probability of a release $P(R \mid A)$ is much smaller (about 5 times) for pressurized cars than for non-pressurized cars since they have thicker shells. Note that $P(L \mid R, A)$. the conditional probability that a release is large once an accident and a release occur, is appreciable for both categories, albeit lower for pressurized cars, which are more durable. ${ }^{1}$

In case of no accident, the conditional release probabilities $P(R \mid N)$ are notably smaller. The zero value for $P(L \mid N, R)$, the conditional probability that a release is large once a nonaccident-induced release occurs, reflects the fact that there were no such outcomes in the historical record used. Hence the risks are estimated to be zero for Table 1 chemicals in

\footnotetext{
${ }^{1}$ For both pressurized and non-pressurized tank cars, the overall probability distribution is a U-shaped function of the quantity released, particularly for pressurized cars containing compressed gases. Given the $80 \%$ threshold in this analysis, only the upper part of the distribution is used.
} 
Table 4

Joint probability results (by tank car type)

\begin{tabular}{lll}
\hline Probability & Pressurized & Non-pressurized \\
\hline$P(A R L)$ & $2.63 \times 10^{-7}$ & $1.87 \times 10^{-6}$ \\
$P(N R L)$ & 0 & $1.00 \times 10^{-6}$ \\
$P(L R)$ & $2.64 \times 10^{-7}$ & $2.87 \times 10^{-6}$ \\
\hline
\end{tabular}

Table 5

Annual frequency of large releases and worst-case impact radius results

\begin{tabular}{lllr}
\hline Chemical & \multicolumn{2}{l}{ Annual frequency of large releases } & Critical Impact \\
\cline { 2 - 4 } & Pre-expansion & Post-expansion & 700 \\
\hline Vinyl chloride & $2.81 \times 10^{-5}$ & $3.31 \times 10^{-5}$ & 45 \\
Sodium hydroxide & $4.38 \times 10^{-4}$ & $5.41 \times 10^{-4}$ & 93 \\
Monoethylene glycol & $3.79 \times 10^{-4}$ & $6.59 \times 10^{-4}$ & 700 \\
Propylene & $1.48 \times 10^{-5}$ & $1.80 \times 10^{-5}$ & 246 \\
Hexene & $3.15 \times 10^{-7}$ & $3.15 \times 10^{-7}$ & 244 \\
Hexane & $3.15 \times 10^{-7}$ & $3.15 \times 10^{-7}$ & \\
\hline
\end{tabular}

pressurized tank cars while the vehicles are stationary. For the other two chemicals, even though the probability of a non-accident-induced large release is very small, the probability of no accident is very high. As a result, the product of these two factors is an order of magnitude greater than the comparable product for the case in which an accident occurs.

$P(A R L)$, the per tank car joint probability of an accident, a release, and a large release is computed using Eq. (1a), i.e., by multiplying the values in the first three rows in Table 3. Likewise, $P(N R L)$, the non-accidental large release probability is computed according to Eq. (1b) by multiplying the probabilities in the last three rows. The sum of these two numbers is $P(L R)$, the joint probability that a release occurs and is large. Stated more simply, this is the probability of a large release. Table 4 provides the values obtained.

We estimate the annual frequency of large releases by multiplying the probabilities in the last row of Table 4 with 12 times the average monthly volumes from Table 1 . This information is provided in the summary table (Table 5) in Section 5 below.

\subsection{Impact radii}

To estimate the critical impact radius for each of the six chemicals, we assumed that the meteorological conditions are as follows: temperature $25^{\circ} \mathrm{C}$, wind speed $1.5 \mathrm{~m} / \mathrm{s}$, and Pasquil atmospheric stability class $\mathrm{F}$. The estimation procedure varied according to the chemical, as described below.

\subsubsection{Vinyl chloride and propylene}

The critical impact radius for vinyl chloride monomer and propylene were calculated using the US EPA's RMP*Comp software for offsite consequence analysis (http:// yosemite.epa.gov/oswer/ceppoweb.nsf/content/rmp-comp.htm). In each case, the selected hazard is an explosion and the critical exposure level is assumed to be 1.0 psi overpressure. If the chemicals are stored as saturated liquids at ambient temperature, then based on their respective densities the total weights of the release quantities will be $104109 \mathrm{~kg}$ for vinyl chloride and $64736 \mathrm{~kg}$ for propylene. EPA guidelines assume that a vapor cloud will be 
formed on release and that if an explosion occurs, it will involve $10 \%$ of the cloud mass. This results in an impact radius of $700 \mathrm{~m}(0.43 \mathrm{mi})$ for each chemical.

\subsubsection{Sodium hydroxide}

Sodium hydroxide is a liquid at ambient conditions. The vapor pressure at $25^{\circ} \mathrm{C}$ approaches zero, hence it will form a liquid pool when released. Being non-flammable, the only hazards will be direct human contact and environmental pollution. We assume that the critical impact range will be the area covered by the pool, which spreads evenly to a depth of $1 \mathrm{~cm}$, with little or no dispersion. A full tank contains 16700 liquid gallons $\left(63.2 \mathrm{~m}^{3}\right)$. Assuming the pool is in the form of a cylinder with volume of $63.2 \mathrm{~m}^{3}$ and height of $1 \mathrm{~cm}$, the radius is estimated to be $44.9 \mathrm{~m}$, or $0.03 \mathrm{mi}$.

\subsubsection{Monoethylene glycol, hexene, and hexane}

These three chemicals also have vanishingly low vapor pressures at $25^{\circ} \mathrm{C}$ and form liquid pools upon release. We assume that a release is instantaneous and that the pool spreads to a depth of $1 \mathrm{~cm}$ in the absence of diking. Ignition probability is low due to the extremely low vapor pressures, but if ignition were to occur, the resulting pool fire would generate a thermal radiation hazard. To evaluate the pool fire consequences, we use the methodology published by the National Fire Protection Association (NFPA, 1988). The critical impact radius is the distance at which the radiation level declines to $5 \mathrm{~kW} / \mathrm{m}^{2}$. This distance is $93 \mathrm{~m}(0.06 \mathrm{mi})$ for monoethylene glycol, $246 \mathrm{~m}(0.15 \mathrm{mi})$ for hexane, and $244 \mathrm{~m}(0.15 \mathrm{mi})$ for hexane.

\section{Summary}

Table 5 summarizes the annual frequencies and the critical impact radii for each chemical before and after the expansion. These results indicate that large releases are uncommon events. For each chemical the increase in the annual frequency due to the expansion is proportional to the increase in the tank car volumes shown in Table 1. Hence, the most significant increase in the risk frequency is for monoethylene glycol $(74 \%)$. The increase in the annual frequency of a large release for all six chemicals combined is approximately $57 \%$. This is a significant increase, but in absolute terms the total frequency remains low, increasing from about 0.0032 to 0.0051 large releases per year. Hence, while the relative increase in the total annual frequency due to the expansion is significant, the absolute value of the annual frequency is still small. The average time between two large spills is about 300 years before expansion and 200 years afterward.

\section{Discussion}

In this section we discuss ways in which the methodology used in the case study can be expanded, and the difficulties associated with such extensions.

The case study focuses on large releases to compute annual frequencies. Theoretically it is possible to account for releases of all sizes. Suppose the probability of a release of $X \%$ of the contents in the case of an accident is given by $P(X \mid A)$. Assume a discrete probability distribution. Denote the critical impact radius for $X \%$ of the contents by $r^{*}(X)$. Then the expected impact radius in the case of an accident would be equal to $E\left(r^{*}\right)=$ $\sum_{X} P(X \mid A) r^{*}(\mathrm{X})$. 
While simple conceptually, this is not a practical approach due to data availability. It is not difficult to compute $r^{*}(\mathrm{X})$ the same way as we did in the case study, but data on the release probability $P(X \mid A)$ are not available for all values of $X$. Nevertheless, one could experiment with different distributions and report the results. Alternately, one could assume the worst (i.e., every accidental release will be a full release; $P(100 \% \mid A)=1$ ) and repeat the analysis. This can be done easily by setting the two probabilities in the third row of Table 3 equal to 1 . Doing this essentially doubles the frequencies for non-pressurized cars and triples the frequencies for pressurized cars.

The case study assesses the risk for one hazard associated with each chemical, in accordance with the understanding reached between the manufacturer and the community as to which hazards would be evaluated. This was done in order to expedite the study and maintain a manageable scope. For example, for hexane we consider the pool fire hazard and for sodium hydroxide we consider the direct contact hazard. However, there are other hazards that might have been worth considering if the scope had be wider. For example, if a fire starts as a result of a hexane release, an explosion is also possible since above flash point, vapor-air mixtures are explosive. Likewise, while sodium hydroxide will not burn, it can react violently with water and numerous other common materials, and generate sufficient heat to ignite nearby combustible materials. Commonly, there is more than one hazard of concern for each product, and the best practice would be to evaluate all possible scenarios to capture the entire risk. In this case, however, the two parties agreed that a single, representative hazard would be sufficient in each case, presumably because they both believed that the conclusions would not change if all hazards had been taken into account.

Another conceivable scenario not considered in the case study is a reaction between two substances. For example, contact between sodium hydroxide and certain organic and inorganic chemicals may cause fire or explosion. If a serious accident involving two tank cars results in a release of contents from both and they come into contact, then a fire or explosion may result even if the chemicals carried in the two cars may not create a fire or explosion by themselves. An even less likely scenario might be a chain reaction including several cars, where one fire or explosion might trigger others, which would put a large impact area at risk. Clearly, such an event is extremely unlikely but the consequence would be very serious.

In Eq. (2) we defined risk as the product of the probability of an undesirable event and its consequence, using the critical impact radius as the consequence. Any uncertainty in the estimated probability or critical impact radius would, of course, translate to uncertainty in the risk estimate. Given estimates of the variance in the probability and the variance in the critical impact radius, and assuming that the probability and consequence are independent, the variance in the risk would be the sum of these two variances and could be used to express the degree of uncertainty in the risk estimate. For a fuller discussion of approaches to evaluating uncertainty in risk analysis, including the Bayesian viewpoint, see Nilsen and Aven (2003).

A useful way to extend the study is to assess the human morbidity and mortality resulting from a release accident. One might be interested in risks to employees and to the public at large. Given the critical impact radii we computed (maximum of $700 \mathrm{~m}$ ), it is unlikely that the public at large would be at risk; hence most of the risks would probably be borne by workers in the yard. The impact areas we computed are considered critical to human health based on toxicological and other health standards. Yet we did not factor in the estimated number of individuals in the critical area at the time of the accident, based on the size of the facility, the activities conducted there, the number of workers involved, and 
their movement patterns. The public at large could also be implicated if, for example, a chemical stored in a tank car formed a toxic or flammable cloud that then traveled towards a populated area nearby. In such cases, one could conduct a detailed simulation analysis taking into account atmospheric conditions (different conditions with associated probabilities), an appropriate dispersion model, the size and composition of the local working and residential populations as a function of the time of day, the specific structures and population magnets in the area, the nature of emergency response resources in the area, the dynamics of emergency response once resources are deployed, and the response of people at risk to emergency response tactics.

\section{References}

ACDS, 1991. Major Hazard Aspects of the Transport of Dangerous Substances: Report and Appendices. Advisory Committee on Dangerous Substances, Health and Safety Commission, London.

Alp, E., Portelli, R.V., Crocker, W.P., 1993. Rail transport risk in the greater Toronto area. In: Saccomanno, F.F., Cassidy, K. (Eds.), Transportation of Dangerous Goods: Assessing the Risks. Institute for Risk Research, Waterloo, Ontario, pp. 75-120.

Barkan, C.P.L., Dick, C.T., Anderson, R., 2003. Railroad derailment factors affecting hazardous materials transportation risk. Transportation Research Record 1825, 64-74.

Cassidy, K., 1993. Hazardous goods transportation: a major UK study. In: Saccomanno, F.F., Cassidy, K. (Eds.), Transportation of Dangerous Goods: Assessing the Risks. Institute for Risk Research, Waterloo, Ontario, pp. 483-510.

CCPS, 1995. Guidelines for Chemical Transportation Risk Analysis. Center for Chemical Process Safety of the American Institute of Chemical Engineers, New York.

Erkut, E., Verter, V., 1998. Modeling of transport risk for hazardous materials. Operations Research 46 (5), $625-$ 642 .

Glickman, T.S., Erkut, E., 1996. What price safety? The tradeoffs associated with responsible routing of tank cars. INFORMS Rail Applications Special Interest Group Newsletter 3 (1), 4-7.

Glickman, T.S., Rosenfield, D., 1984. Risks of catastrophic derailments involving the release of hazardous materials. Management Science 30 (4), 257-277.

Kirchner, J.R., Rhyne, W.R., 1993. The risks of handling vs. transporting dangerous goods. In: Saccomanno, F.F., Cassidy, K. (Eds.), Transportation of Dangerous Goods: Assessing the Risks. Institute for Risk Research, Waterloo, Ontario, pp. 385-400.

NFPA, 1988. Society of Fire Protection Engineers Handbook of Fire Protection, Section 2, Chapter 4. National Fire Protection Association, Quincy, Massachusetts.

Nicolet-Monnier, M., Gheorghe, A.V., 1996. Quantitative Risk Assessment of Hazardous Materials Transport Systems: Rail, Road, Pipelines and Ship. Kluwer, Dordrecht.

Nilsen, T., Aven, T., 2003. Models and model uncertainty in the context of risk analysis. Reliability Engineering \& System Safety 79 (3), 309-317.

Olekszyk, P., 1993. Analyzing routes for the transportation of hazardous materials including radioactive waste and spent nuclear fuel by use of effective risk estimation. In: Moses, L.N., Lindstrom, D. (Eds.), Transportation of Hazardous Materials. Kluwer, Boston.

Purdy, G., 1993. Risk analysis of the transportation of dangerous goods by road and rail. Journal of Hazardous Materials 33 (2), 229-259.

USEPA, 1999. Risk Management Program Guidance for Offsite Consequence Analysis, Office of Solid Waste and Emergency Response, US Environmental Protection Agency EPA 550-B99-009, April.

Vogel, A., Vondra, J. 2001. Assessment of risks of the carriage of dangerous goods by rail - state of the art report, European regulations. In: Proceedings of the 12th European Conference on Safety and Reliability, Torino. 